Article

\title{
District Council Members and the Importance of Member Involvement in Organization Renewal Processes in Swedish Forest Owners' Associations
}

\section{Thomas Kronholm * and Dianne Staal Wästerlund}

Department of Forest Resource Management, Swedish University of Agricultural Sciences, Umeå 901 83, Sweden; E-Mail: dianne.wasterlund@slu.se

* Author to whom correspondence should be addressed; E-Mail: thomas.kronholm@slu.se; Tel.: +46-90-786-8402; Fax: +46-90-786-8125.

Received: 18 April 2013; in revised form: 29 May 2013 / Accepted: 6 June 2013 /

Published: 14 June 2013

\begin{abstract}
The objective of this paper is to examine the organization renewal process in forest owners' associations and the role of members in this process. Based on 15 qualitative interviews with district council members in a forest owners' association, we describe the characteristics of today's elected member representatives in terms of their motives for volunteering, their relationship with the organization, and the organizational practices and routines of the renewal process. It is shown that most district council members are traditional forest owners with a family history within the association and that the district councils are therefore not representative of all member groups. We thus argue that it will be important for the renewal process that the associations carefully consider how they want to be perceived by both current and potential members in order to encourage the involvement of different owner groups. The election committees, which prepare the elections to the councils and board, play an important role in the associations' renewal processes and must become more active in their search for suitable candidates.
\end{abstract}

Keywords: member organization; volunteer; reproduction; identity; relationship 


\section{Introduction}

Almost one hundred years ago, a large group of Sweden's private (non-industrial) forest owners organized themselves into associations (cooperatives), which became important actors in the markets for wood and timber [1]. They started as small, local associations of farmers who were dissatisfied with the way that a few large companies were able to dictate terms in the timber market. Through cooperation, the farmers improved their market position by negotiating better prices and managed to create a better functioning market for wood products. From the outset, the associations were founded on traditional cooperative values and have been governed by the principle of one man, one vote [2]. Today, approximately 110,000 forest owners (out of 330,000 forest owners in Sweden) with a total of 6.2 million ha of forest land belong to one of the four major forest owners' associations; Södra, Mellanskog, Skogsägarna Norrskog and Norra Skogsägarna, all of which in turn belong to the Federation of Swedish Farmers [3]. All four associations have similar organizational and governance structures, with a professionally run business organization and a democratically steered member organization. According to Normark [4], member-owned companies usually have an organizational structure that resembles an hourglass, with power being distributed across several levels due to the complexity introduced into the decision-making process by having numerous members. Inspired by Normark's hourglass model, we created the model outlined in Figure 1 to describe the organization and governance structure of the forest owners' associations.

Figure 1. The organization and governance structure of forest owners' associations in Sweden.

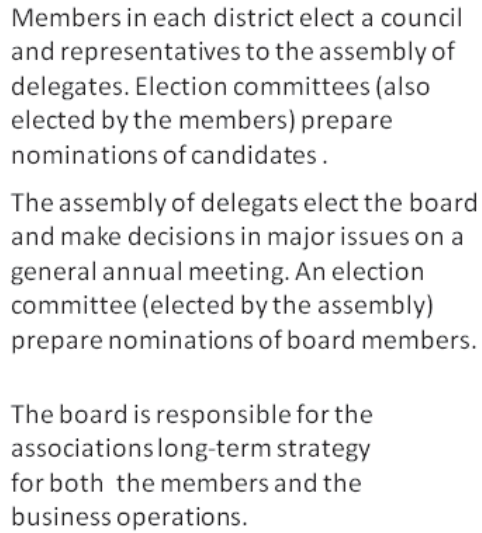

The board is responsible for the associationslong-term strategy for both the members and the business operations.

The association's business operations are organized and managed in similar way as in investor owned companies.

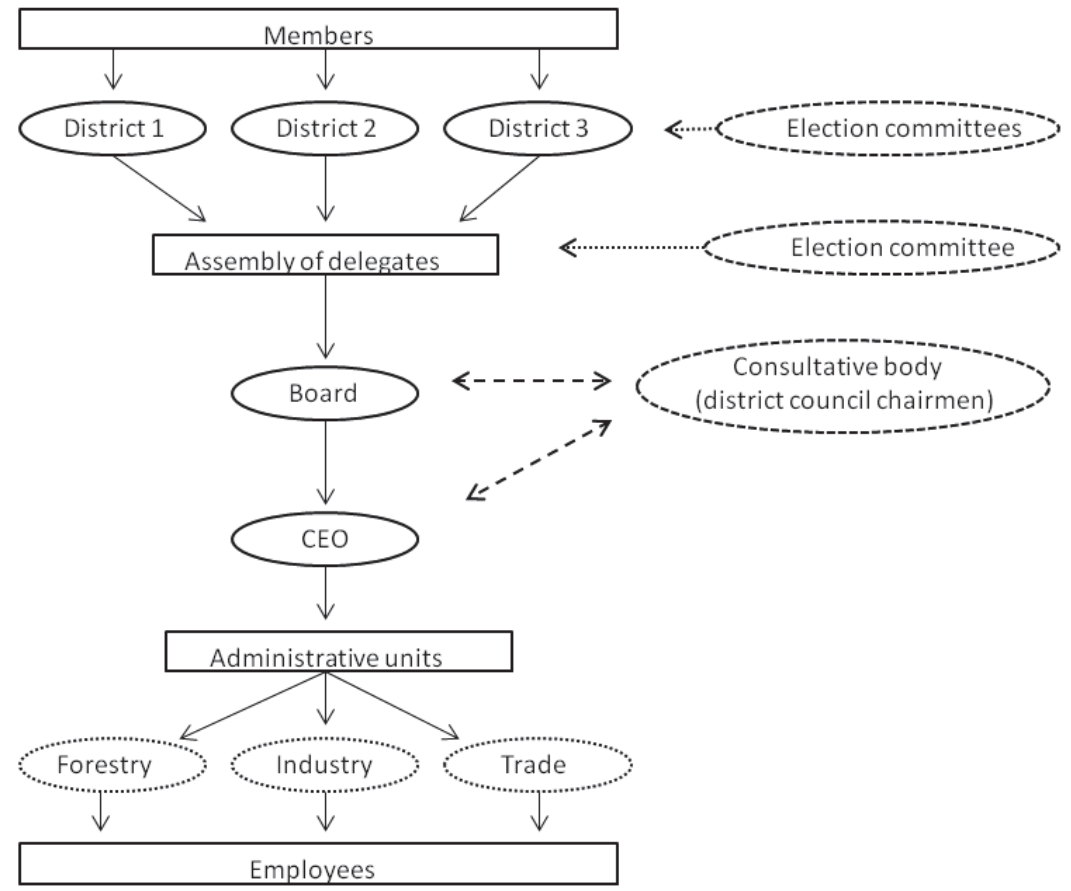

While the mission of forest owners' associations has not changed greatly since their introduction, society and forest owners as a group have changed a lot. Previously, most of the privately owned forests were held by farmers but modern forest-owners are a much more heterogeneous group [1]. Urbanization has created a situation in which many forest-owners live and work further away from their estates than was once the case, and this change has been paralleled by changes in the ownership 
structure and female ownership is becoming more common [5]. Karppinen [6] identified this transfer of forest ownership, via inheritance, as the most significant structural change within the forest owning group. Finally, modern forest owners are less dependent on their forests as sources of work and income [7].

Authors such as Inglehart [8] have shown that societal development of this sort tends to change people's values, creating differences between generations. Nordlund and Westin [7] confirmed that the new types of forest owners, who are more likely to be non-resident and female, hold different values than do traditional resident owners. Women tend to place a greater emphasis on the recreational value of their forests, and non-resident owners are less interested in forest revenues than resident owners. This might affect their forest management practice in a way that is not fully compatible with the current focus of the forest owners' associations, which are primarily concerned with timber production [1].

This could pose a significant challenge for the associations in the near future because their current member base is relatively old, as are forest owners in general. In 2010, more than 110,000 of Sweden's forest owners were at least 65 years old [3]. A market analysis conducted by Swedbank and LRF Konsult [9] estimated that forests to a value of 76 billion SEK ( $\$ 12$ billion) will be transferred to new owners within five years. This means that the forest owners' associations will go through a period of change, during which older members will leave and will have to be replaced by a new generation of owners whose values may diverge from those of traditional forest owners, both in general and with respect to forestry in particular. In addition, there are other factors that could make it hard for associations to recruit and engage new members in the future. In general, people are becoming less interested in joining and giving time to associations of all kinds. This process was described by Vogel et al. [10] in a report about the engagement of people in associations during the period between 1992 and 2000. It was found that Swedish associations have experienced a general decline in membership that was not restricted to any individual type of association. Second, association members are becoming increasingly passive, i.e., they pay their membership fees but do not take part in any of the association's activities. It has also become harder for the associations to find people who want to take on roles as trustees or volunteers. However, the amount of time spent on these activities increased over the same period, meaning that fewer people were doing more work in order to keep the associations running. Finally, it was shown that younger people (under 35 years of age) are less interested in becoming members of associations. This is a major long-term problem, since departing members are not replaced. Notably, this issue is not confined to Sweden. For example, in his famous book "Bowling Alone", Putnam [11] showed that people's relationships with associations in the USA have also changed over the last few decades.

So far, the forest owners' associations have been an exception to the rule in terms of their membership numbers, since they have been successful in recruiting new members during recent years [3]. However, an increase in the number of memberships does not necessarily mean that all of the new members will embrace the organization's ideology; people may join an association for a wide range of reasons [12]. For example, forest owners may have joined to take advantage of the good timber prices offered by owners' associations in recent years. Because members got a price premium when selling to the association, it has been economically beneficial to become a member. One could thus reasonably ask whether the forest owners' associations have been "buying" their members rather than recruiting them. In addition, new members may be retained because the members of the association need to apply to exit [13]; in many other associations, members must actively renew their membership on an annual 
basis. Forest owners' associations may thus have many passive members. However, the associations' current organizational structure requires that people be willing to get involved in the associational work. In this respect, the cooperatives in the agricultural sector are experiencing similar problems to those encountered by other members' associations. For example, relatively few people attend their meetings [14]. In some cases, less than $10 \%$ of the association's members attend their annual general meetings [15]. One possible implication of this development is that the organizations may have to change their governance structures and decrease their emphasis on being steered by their members. Instead, it may be necessary for them to become purely member-owned companies that are managed and controlled exclusively by professionals. Such developments are common in organizations like the forest owners' associations [16-18].

Because of these circumstances, the forest owners' associations are starting to consider ways of renewing their organizations and the services they offer in order to meet these present and future challenges [19]. However, renewal does not come by itself nor does it develop from nothing. The organizational renewal process, which has been described as a reproduction of memberships by Stryjan [20], is affected by the organization's existing culture and practices, since these affect the recruitment process and are based on the members' perceptions of what the organization should stand for. Based on this theory, the members of forest owners' associations are expected to play a crucial role in the shaping of their organization's future and the development of the organization will depend on what its members do and don't do and what kind of inputs they contribute with to it. But the current organization has also been shaped by the previous members who have established the current traditions and practices in the organization. Organizational reproduction can thus be viewed similar to biological reproduction, i.e., we are all shaped by our parents and the environment we have grown up in and in turn will shape our children and develop new practices within our family as the composition of it changes. In particular, those who involve themselves in the organization and take on voluntary roles as district council members are thus expected to contribute in the process as they have been assigned by other members to have the main responsibility to act as "parents" of tomorrow's organization. However, few studies have examined organizational renewal within forest owners' associations and little is thus known about the roles played by members in this process or why they volunteer to do this work. Therefore, we find it both important and interesting to study those members who have volunteered for this position and who thus will have strong influence in the reproduction process and thereby in the renewal of the association. As Bussell and Forbes [21] argue, when recruitment of new volunteers become harder, it gets even more important for organizations that are in need of volunteers to develop their understanding of this group of people.

The objective of this study is therefore to examine the reproduction (organization renewal) process in a forest owners' association and the role of the district council members in this process by investigating the following questions:

- Who are district council members in the present organization?

- How to understand their motives and driving forces for volunteering?

- How is involvement stimulated according to these members (e.g., recruiting, possibilities to contribute to the organization, etc.)? 
- How does the democratic process work within the organization and how do these members perceive their influence in organizational steering processes?

\subsection{Theoretical Background}

In conventional organizations, organizational renewal is generally regarded as the responsibility of the managers. In member-steered or self-managed organizations, the members have a much greater degree of responsibility for addressing problems as they arise and for the process of organization renewal. According to the reproductive perspective, a cooperative organization should be "manned, steered and continuously (re)designed by its members" [22]. In Swedish forest owners' associations elected member representatives have been assigned a special responsibility for this process through the organizational structures and democratic procedures that have been established in order to manage this type of association [4]. However, the management's role should not be neglected and we will return to this issue.

The reproductive perspective was introduced by Stryjan [20] in his work on cooperative organizations. The renewal process in a member-steered organization is described as a continuous loop in which members' assumptions lead to decisions, which in turn create new organizational routines and practices, which themselves generate new assumptions. This means that we "at any given point in time would be dealing with an organization 'of today', shaped by yesterday's members, is populated by today's members, and which ought to be keyed for the shaping of tomorrows organization and the recruitment of its would-be-members" [22]. The development of the organization will depend on factors such as (i) the recruitment of new members, (ii) the shared identity of the organization and its members, and (iii) the inputs the members contribute to the organization. Individual members can provide four types of input: involvement, protest/voice, loyalty and exit [20]. Exit from an association is often how people show dissatisfaction and it provides input to the organization as it changes its composition of members. However, exit is sometimes not that easy when the alternatives are few and the process complex [23]. This might be the case for many members in forest owners' associations, since the associations are geographically divided and exit demands active resignation. Loyalty is important for any organization but loyal members will not always contribute with any creative inputs to the reproduction process [22]. Therefore, this study focuses primarily on the creative inputs that members can contribute to an association rather than exit or loyalty.

The involvement of members is often seen as a strength of democratic organizations and should be welcomed and encouraged by them since it is a source of innovation. However, strong involvement from many members can also be seen as problematic for the organization and might even be fought against by management since it makes steering processes more complicated and takes a lot of time and effort. According to Stryjan [22], the ways the organization handles this issue will determine what type of members it will have in the future.

The growing size of the associations has lead to changes in their business structure as well as their management and governance, and several authors have described the growth-related problems experienced by traditional cooperatives and associations. Building on concepts from population ecology, Nilsson et al. [16] discuss how associations will imitate the structures of other investor-owned firms in related business sectors. According to Giroux [24], this happens because the environment in which the 
association operates has certain expectations about how business is done, and deviating from this form could potentially reduce the organization's perceived legitimacy within the market. Forest owners' associations thus face the challenge of combining a more business-oriented organizational structure with the traditional practices and values of their member organizations. In addition, the growing size and increasing heterogeneity of their member bases could create steering problems because the members may lack the ability to effectively control the organization's managers [25]. This could cause the members to feel dissociated from the organization, or to feel that they do not understand how it operates. In turn, this dissociation can produce a growing number of dissatisfied, uninvolved members who do not trust the organization and effectively become free-riders who do nothing beyond taking advantage of the hard benefits obtained through membership [16]. In combination with changing market conditions, this can further increase the power of the management in a self-sustaining process.

Democratic organizations thus have the tendency to evolve towards a situation in which the power of the members decreases and that of the managers increases. As noted by Echeverri [14], when fewer members attend meetings and the primary focus of the organization shifts towards economical matters, a conflict is created between the organization's historic ideals and the corporatization process. This ultimately leads to a less democratic organization with increased administrative power. According to Chaves and Sajardo-Moreno [18], the evolution of democratic organizations into administrative organizations proceeds via four stages. In the beginning, ideology and volunteerism dominate and the members control what happens in the organization through their legislative power. In the second stage, the organization places an increasing emphasis on economic factors, creating a need for administrators and managers. Some power is thus transferred to executives, reducing the organization's idealism and voluntarism and thus the involvement of the general member base. In the third stage, managerial power increases further, and the organization's original social ideology is largely replaced by market values. Less focus is placed on social activities and the business becomes more complex, which imposes new demands on the decision-making process. As discussed above, this limits the members' opportunities to exercise control over management. The fourth and final stage is when the administration has gained total control over the operation. The business, its structure and the information flow have become so complex that no member group is capable of controlling the managers. A new business model that focuses exclusively on the organization's economic development may be introduced, along with managers that are imported from external sources. Because Sweden's forest owners' associations have become or are becoming large, and even multi-national, businesses we expect that they are currently somewhere in the later stages of this process.

To prevent managers from taking complete control, the association's members need to get involved rather than just being passive. Members of forest owners' associations can do this by going to meetings or by taking on voluntary assignments, e.g., as representatives in the district councils that act as consultative bodies for the association's board and management, and arrange member activities. Wilson [26] defines voluntary action in terms of giving away time and effort for free (or below market price) to benefit a person, group or cause. According to Penner [27], volunteerism has four distinct attributes. First, it is a planned action. Second, it should be non-obligatory in the sense that the person volunteering should not feel a personal obligation towards another person as they might when helping a close relative who is ill. Third, the time-span is usually longer than just during one occasion. Finally, it is typically done within an organizational context and is thus more organized than other forms of 
help given to individuals or causes. Wilson [26] further argues that voluntary action should be separated from being active in an organization run by volunteers, meaning that those who are volunteers are giving time and effort to produce services that other individuals can consume. The member representatives in the forest owners' association's district councils can thus be categorized as volunteers, although they need to be elected by the other members to become part of the council. This group of members is therefore of primary interest when trying to understanding the reproduction process, as it can explain the selection process of what Stryjan [22] calls the organization's corpus of members.

Previous studies have shown that people's demographic backgrounds and personal motives will influence on the decision to volunteer. According to Wilson [26], young people will be more likely to volunteer if their parents have done so. This might be because the parents act as role models and also pass on certain values and motivations to their children. Whether this increased likelihood of volunteering remains in older ages is not certain. However, since most people in Sweden become forest owners through inheritance, we can assume that some family traditions and forestry-related values are also passed on to the new owners. This assumption is supported by Malmqvist [28], who found that 75\% of the children of current members in one forest owners' association are interested in becoming members when they become forest owners. It is thus reasonable to believe that many of today's council members will have a family tradition in the association.

It is generally accepted in the literature that the likelihood of volunteering increases with the individual's level of education. Different authors have proposed various explanations for this phenomenon. According to Wilson [26], education increases people's awareness of different problems and gives them the self-confidence to act on those problems. Further it is argued that people with higher education are more frequently asked to volunteer, for example in cases where the organization needs specific skills and knowledge, which more highly educated people could potentially bring. Penner [27] suggests that people with higher education and who come from a higher social class need something besides their ordinary work in order to find additional meaning in their life. However, the level of education is not as apparent in all types of voluntary organizations and positions. In some type of organizations social skills might be more important and thus lower the requirement for formal education [26]. Given the history of forest owners' associations, their strong ideological foundations, and the tasks of the district council we find it reasonable to expect that the level of education will vary among the representatives. Higher education might be more important for those who are recruited to the association's board, which is responsible for financial matters and making strategic business decisions.

An individual's work status also affects the likelihood that they will take on voluntary work. People with jobs are more likely to volunteer than unemployed persons, and people with high-status jobs volunteer even more frequently. Further, the possibility to have flexible working $\mathrm{h}$ will affect volunteerism [26]. Work status might thus be one reason to why Vogel et al. [10] found that young people today are less frequent to take on voluntary work. Youths today begin their working life later than was previously the case, and many young people are also lacking employment. According to official statistics, $18.6 \%$ of Swedish youths between 20 and 24 years of age were unemployed in December 2012 [29]. Unemployment may also affect the individual's social network, which is an important factor since people are more likely to take on voluntary work if friends ask them to join an organization then if some stranger does [26]. In light of this, it is reasonable to believe that council members will generally have some form of employment, or at least had when they were recruited. 
Additionally, we expect that the representatives have been recruited by people they know within an organizational context, either the forest owners' association or some other organization.

Finally, people will have some personal motives for joining an association and becoming involved in it. Clary and Snyder [30] identified six different categories of motives for people to volunteer:

1. Values - A desire to help others;

2. Understanding - A desire to gain experience and learn new things;

3. Enhancement-A desire to feel good;

4. Career-A stepping stone to future employment;

5. Social-Friends with same interests;

6. Protective-escape from personal problems.

Among these motives we find both egoistic motives as promoting one's own career or to learn new things but also more collectivistic drives that emphasize the well-being of others. Penner [27] argues that some people have a "prosocial personality", which is characterized by strong feelings of empathy and helpfulness. However, his study refers to people who have joined different types of community service organization with focus on social issues, and therefore the term "prosocial" might be delusive for our study. Nevertheless, the elements that constitute this personality are quite general and thus useful here because to feel responsibility and to work for the well-being of others may well apply also for the forest owners' associations which traditionally were built on collectivistic values. This personality trait is therefore also expected to be found among district council members.

\subsection{Summary}

With the starting point in Stryjan's reproductive perspective, we have described how members through their assumptions about the association and their possibilities and willingness to contribute with inputs to the organization will determine how the organization develops over time. We have also explained the potential risk of increased managerial control that these kind of democratically governed organizations faces and why it is important for members to be engaged in the organization's operations. Further we have described how people's personal characteristics will affect their likelihood of volunteering, and how motivations for volunteering range from the purely egoistic to more collectivistic ones. To summarize this complex process we modified Penner's [27] conceptual model of sustained volunteerism by incorporating Stryjan's [22] reproductive perspective (Figure 2). Since Penner's original model does not describe how the volunteers will affect the organization's attributes and practices through the inputs they will contribute with, we find that these two views are complementary in a way that is useful for our purposes. By inspection of the figure, we can identify the loop of reproduction which will constantly be ongoing inside the organization. The model can thus serve as a useful guide when analyzing who the district council members of a forest owners' association are, why they have volunteered, how they perceive their role in the organization and in what ways they are able to contribute with inputs to the organization in order to alter its attributes and practices and thereby promote its renewal. 
Figure 2. Our modified version of Penner's conceptual model [27] describing sustained volunteerism. Solid lines represent strong causal relationships while dashed lines denote weaker ones. The backward curved dotted (red) lines represent Stryjan's idea [22] that the members will affect the organization's attributes and practices, which in turn determine who will decide to join the organization. This process can thus be seen as continuous loop.

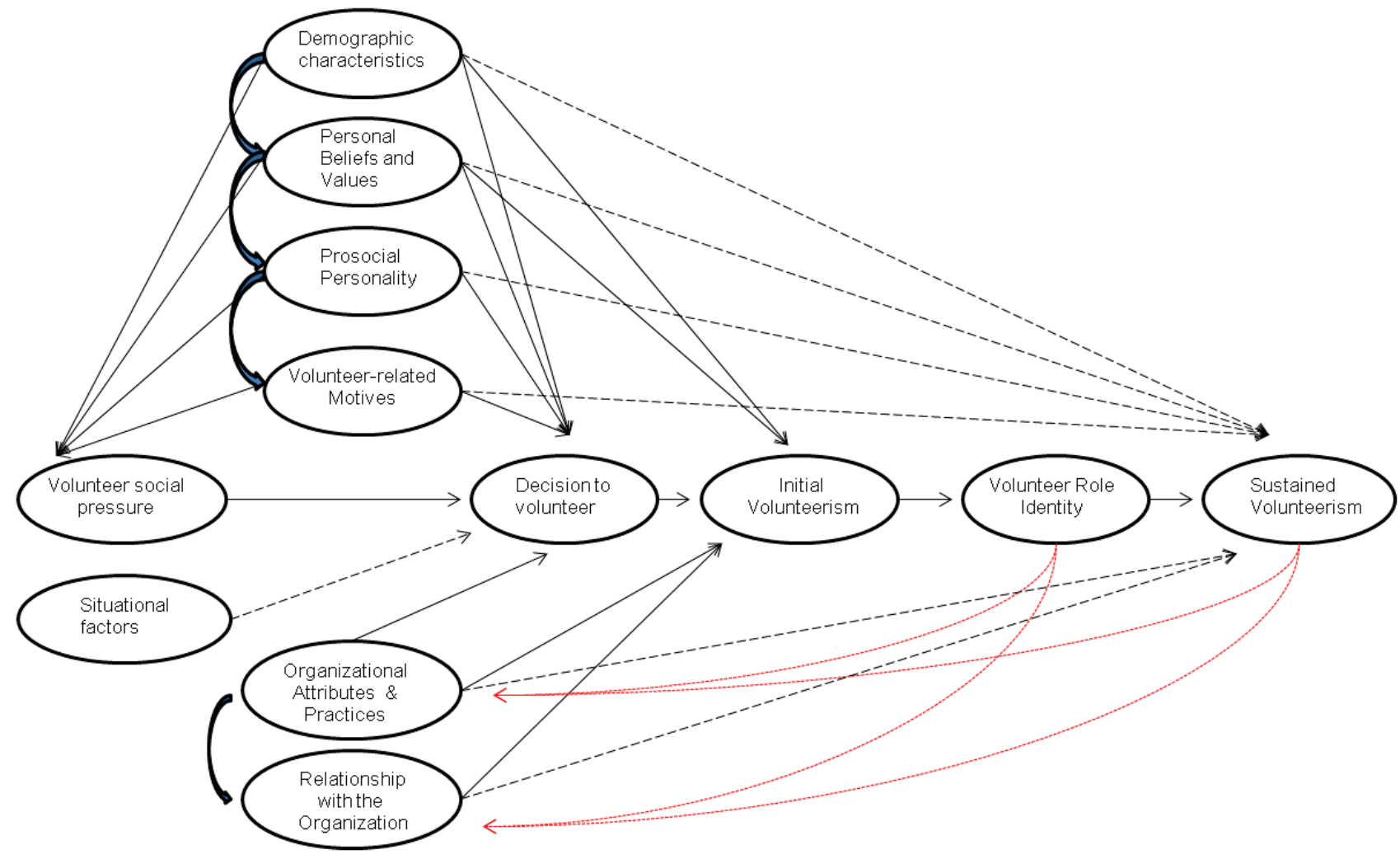

\section{Materials and Methods}

The empirical data used in this study was collected through 15 qualitative interviews with district council members of the forest owners' association Norra Skogsägarna, which is active in the northern parts of Sweden. The data were collected in 2011, at which time the association (cooperative) was owned by 15,908 members who together owned 1.06 million ha of forest land. The organization had about 400 employees and an annual turnover of 1688 MSEK [31]. Due to its wide geographical area, the association was divided into 27 districts (or SBOs-Forest Management Areas) and four regions. Each district had a council of elected member representatives (170 district council members in total) who were responsible for arranging member activities and to serve as consultative bodies for the association board. The members of the district also elect delegates to attend the association's general annual assembly meeting; the association's highest governing body.

Based on the theoretical framework, the elected member representatives in the district councils are members who should play central roles in the association's reproduction process and were therefore of great interest for our study. Consequently, it was important to get a balanced group of interviewees from this sample group in order to get information from multiple angles [32]. To ensure that this was achieved, we used three guiding criteria when selecting interviewees. 
(a) Geographical location: Norra Skogsägarna has a large area of operations, which made it important to select respondents from different districts in order to capture diversity or variety between its districts and regions. For example it could be expected that regional traditions as well as different forestry and market conditions might create different motives and driving forces for forest owners to volunteer and get involved in the association. It was also taken into account that the respondents' views on their possibilities for involvement in the association's democratic process could be affected by physical distance to the association's headquarters and other important meeting places. The final selection of districts was made through a convenience sample. In the end, 13 of the association's districts and all of its regions were represented in the study;

(b) Gender: The theoretical framework indicated that male and female forest owners might have different values and thus have different motives for joining and becoming active in a forest owners association. Female council members might also have different experiences and views concerning the association's routines and practices since they are in minority ( $20 \%)$. Six female and nine male council members were interviewed, meaning that female members were slightly overrepresented among the interviewees relative to the situation in the councils. For analytical purposes it was considered more important to have a sufficient selection of respondents in each group in regard to all three criteria used than to have statistically representative groups of respondents;

(c) Seniority: It was assumed that there might be differences between the individuals selected as district chairs and ordinary district council members. These differences might reflect differences in time spent within the organization, access to information, scope for exerting influence, values, and other factors. For the same reasons, it is reasonable to expect that district chairs would be able to provide more inside information on the functioning of the association, and so the interview group included nine district chairs and six ordinary council members. The sample includes both male and female chairpersons.

All fifteen interviews were done as semi-structured, face-to-face, interviews that were conducted during August 2011. The duration of the interviews ranged from $50 \mathrm{~min}$ to $2 \mathrm{~h}$, with an average duration of one hour. An interview guide was constructed based on the model that summarized our theoretical framework (Figure 2) and the interviews were organized in two main themes; the person (demographic characteristics, prosocial personality, volunteer-related motives, personal beliefs and values) and the organization (attributes, practices and the respondents relationship to it). Questions related to role identity and the decisions to volunteer were present in both themes. Open ended questions allowed the respondents to freely share their views, thoughts and experiences within the different topics and follow up questions for more detailed or clarifying answers were asked when needed. The interviews were recorded and listened to after each interview. Once all of the interviews had been conducted, they were transcribed in order to make the data easier to sort and manage during the analysis. The transcripts were prepared as what Pointdexter [33] describes as "rough transcripts" or "content-only", meaning that details in the interviews such as pauses or changes in tone of voice were not considered. When structuring the interview material, and our analysis of it, we focused on the three main constituents of the reproduction process: the replenishment process, the shared frame of reference 
among members, and the possibilities for members to provide input to the organization. Approaches of this sort, with conceptually grounded themes and patterns, are widely advocated in the literature [34]. By reading and comparing the interview transcripts we identified similarities and differences in the respondents' answers and summarized the results together with descriptive citations. Two important themes that had not been explicit in the interview guide were identified: the chairperson conference and the election committees. Our analysis has thus been theoretically driven and during the whole process, from the interview until writing the paper, we continuously compared and evaluated our findings against the theoretical framework presented in the paper. Our main focus has been on the three parts of the reproduction process and our discussion is thus also divided into these three sections. First, we discuss the replenishment process and the absenteeism of new categories of owners in the district councils and give some possible explanations to why the renewal process seems to be slow. Second, we discuss how district council members' role identity might affect the organization in its replenishment process and its interaction with members. Finally, we discuss the respondents' views on their possibilities to contribute with inputs to through the democratic process and organizational. Also, in all three sections we also share our view on how the association could improve the organization's renewal process, based on the reproduction perspective. In the concluding part we present our main findings and point out what we see as the most important factor for the future renewal process of the forest owners' association and thereby its survival in a changing environment.

\section{Results}

\subsection{Characteristics of the District Council Members}

The individuals interviewed were between 41 to 70 years of age, with a mean age of 52 . This is very close to the mean age of all elected representatives obtained from the list of council members in 2011, which was 54. A majority of the respondents had a background in agriculture and lived on or close to their forest property, since they had in most cases taken over the farm/property from their parents. Four of the respondents had milk production as their main business operation, and another three had previously kept animals but had since moved into other areas of employment within the agriculture or forestry sectors. Additionally, one respondent worked in agriculture as an employee but had never owned animals. Two of the respondents were or had been growing crops on some scale. Forestry accounted for $10 \%-20 \%$ of the total operations among those who combined farming with forestry. Only one respondent reported that forestry was the main source of income. Of the respondents who were not farmers and did not work in agriculture, two worked in forestry and had their own companies in this sector. There was also one respondent who ran a small company outside the forestry sector. Several of the respondents had been politically active, for example by being part of a municipal council or by being involved in The Federation of Swedish Farmers (LRF).

There was considerable variation among the respondents with respect to the sizes of their forest holdings. The respondents owned between 30 and 700 ha of forest land and the time they had owned their forest varied between 10 and 45 years. In most cases, they had either inherited or bought the forest land from family members. A few respondents had subsequently purchased additional forest holdings from people outside their immediate families when areas of land adjacent to theirs became 
available. Only one respondent had become a forest owner by buying forest on the open market, and he did this together with his father who was a forest owner at the time.

The respondents' levels of education varied significantly, from upper secondary school (gymnasium) to university. Most of the respondents had a level of education between these two limits, having taken some form of shorter occupational training or courses relating to agriculture or forestry. However, some had qualifications in other fields, such as nursing.

The respondents expressed that they had a huge interest in forestry since they have grown up with forestry in the family. Common expressions on this issue were: "My interest in forestry grew very early, because I used to join my father when he went to the forest to cut firewood. There was always something that needed to be done" or "Planting one has been doing since childhood, with mom and dad. Even if I didn't think it was much fun at the time, it was something that had to be done and I did it. So being in the forest has always been part of my life. Also, we live out in the woods so I guess it is quite natural".

All except one respondent said they did some work in their own forests, but most of them said that they purchased services when harvesting. Much of the work was regarded as a hobby at the same time that it was seen as cost efficient to do it themselves: "During winter I try to work 2-3 days a week, between milking times. I go out and 'clean up' as I use to say. No final felling, mostly cleaning, thinning or something in between, as well as collecting firewood to heat the house and some planting". The respondent who did not do forestry work spent some time in the forest hunting and participating in recreational activities.

\subsection{Motives for Volunteering}

Being asked to volunteer may not be a motivational factor in the theoretical sense, but was the spontaneous answer from the respondents on the question of why they had become an elected representative. It was expressed by the respondent as: "It was the election committee that called me", "well it was because I was asked" or "someone had suggested me". Few respondents gave any indications that they had strived for the position, in the sense that they actively had run a campaign to become elected. They had been going to meetings, visited forest days, or participated in other member activities, and thus showed their interest in the association before being asked but no one said that they had nominated themselves for the position. A question from the election committee was reported to have also encouraged those with limited experience in the association and who did not know what the requirements or expectations of council members were.

One of the commonly-reported initial motivations for volunteering was a curiosity and desire to gain more insights and information from the association. One respondent put it this way: "I thought it sounded interesting to get a more central position in the association, to get more information and access into the organization". Linked to this access of information was the motivation to learn more and gain new knowledge, both about the association and about their own forestry. One respondent explained that as a newcomer in the organization, she had not known much about the business of the association and the district council: "It was simply that I was curious and wanted to learn more. I was quite ignorant at the time". For this respondent, the first period was much about learning the organization's routines and practices by attending conferences and courses that were arranged by the 
association. After gaining more knowledge, other types of motivations came into existence, such as the power to influence.

For another female respondent, it was important to learn more in order to feel that she could be on an equal level as her brother, who had a forestry education. For her it was a way to be taken seriously and to increase her confidence regarding forestry, which she considered important because she and her brother owned their forest land jointly. Partly for the same reason she started hunting, in combination with a father who had been keen to encourage her to try different things. Involvement in the organization thus offered her opportunities to gain more knowledge and experience as well as self enhancement.

Becoming an elected representative gives members better insight in the association and should thereby enable them to increase their influence on the organization. However, it was not very common that respondents had volunteered with this as a clear motive, as already stated above. None of the female respondents said that they had taken the decision to volunteer because they wanted more influence on the association. However, the importance of this motivation was reported to have increased over time. One of the female respondents described the process as: "one is always shy in the beginning and does not say much, but gradually you discover that you actually can do things. You can actually exert influence through different channels".

It was more common for male respondents to describe the ability to exert influence as a motive for volunteering. Some expressions along these lines included: "You get irritated about things, you want to get involved and have influence", "I want to participate, drive change, and act on issues" or "you see that you could step in, have some influence, and change things for the better". In contrast to the female respondents, no male respondent expressed that they had limited knowledge when they first volunteered, and several also noted that they had attended many meetings prior to volunteering, which had given them insights into the different issues that were on the agenda.

In addition to the respondents' common interest in forestry, they also expressed other personal interests for becoming a volunteer in the forest owners' association. One of the female respondents had volunteered because of her engagement on the issue of female representation in the councils. She had raised a question about female representation during a district meeting and was later nominated to join the council.

A more business oriented reason to join could also be found among the respondents who mainly referred to the association's role of keeping timber prices up and the importance of securing the association's existence as a way of maintaining favorable market conditions. This aspect was most strongly emphasized by the respondent who relied on forestry for his income: "forestry is my main occupation, so I wanted to get involved in the forest owners association as an extension of my own business".

There were also respondents who reported that it feels natural for them to volunteer because of their personal beliefs and values, which could be expressed as: "I believe in working together for a common cause. That it is possible to have a joint ownership and governance".

The respondents often mentioned their father's importance for their choice to become members in the association and that they had inspired them to become active in the association. For one it was never seen as an option to choose another business partner: "It was a given because I have grown up with a father who would not appreciate it if I did not join Norra. It was so natural, I have grown up with it...We have always had some forest inspector at the kitchen table". Other respondents also 
acknowledged their fathers' contributions: "Then I got a little bit involved in the association, largely because of my dad. He was part of the election committee and I was asked to join the council. My grandfather has also been involved in the forest owners' movement". A third respondent emphasized this phenomenon whereby membership and district council duties seem to be passed on within the family: "I can put it like this; I took over after my father. He sat on the district council and a few years after he stepped down, I came in. Another one from the village took over from his dad and a similar thing happened with a guy from a nearby village who took over from his brother, who had taken over from their father. So it does very much run in the family".

In some cases, the respondent's fathers or grandfathers had been active from the start when the local associations initially were founded and for them it was completely natural to become part of the association because it had always been the business partner in the family and they had well established personal contacts with professionals in the association.

Social contacts were an important part of why respondents felt that it was fun to be involved in the councils work and the association in general. Their volunteering gave them a chance to meet people with similar interests ("like-minded") and to extend their networks. For the farmers and others who had quite isolated/individual jobs, it was a way to get out and meet other people. One respondent who had previously had a regular job but was now working at the farm highlighted this aspect: "Now that I am at home, working with the animals and stuff, it is fun to be involved and meet other people". The social factor was also emphasized by another farmer who felt that: "Half the pleasure is in getting together with other people and drinking coffee, the other half is the formal meeting". Meeting people was also important for the non-farmers: "It has been fun meeting people. We have had many laughs together and I think that is very important that you can get to know each other and socialize in a convenient way".

However, one respondent who had an administrative job with a lot of professional meetings expressed different thoughts about the social aspect of meetings: "One thing that I sometimes find a bit boring, as an elected representative who is involved with the association, is that you have these meetings, you get this information, you plan and carry out the activities, and all that feels a bit like my regular job. I often say that I want to spend more time in the forest. All these things around meetings I get at work".

The respondents expressed that they feel good when they can contribute to the organization and its members: "I guess it is about getting the members to feel satisfied, as owners and members. And if there are any problems you try to solve them". They also expressed feelings of responsibility for the organization and the wellbeing of its members: "I want the association to live on. Because I see that the companies are in quite a good position today against the associations. The movement is weaker today than it has been during the last 30 years. People do not see the benefits of the association, the collective". The respondents valued the collective and found it rewarding to help other people with their problems and to improve the overall situation for forest owners.

Representing and looking after the interests of weaker owners were mentioned as important reasons: "(I think it is important) that you get the money you are entitled to, not more or less, that it does not go only to those with the loudest voices. That, I dislike". Member equality was also important for some respondents, who considered it essential for the association to treat all members equally without regard for the size of their holdings. This meant that the association should also be open to members with varying degrees of knowledge and that all forest owners should feel welcome and that they would 
derive some benefit from being part of the association. One respondent stated that everybody should "feel at home" in the association and not feel stupid when attending some meeting or activity. One way they had tried to achieve this goal was by designing courses suitable for newcomers to forestry who might be unfamiliar with the expressions used in (for example) courses on forest management plans.

\subsection{Role Identity}

The respondents generally had similar perceptions of their roles in the organization. A common response was that "we represent the forest owners, the thoughts and ideas of forest owners, and their expectations of the association". Their views on how this mission should be carried out were also quite uniform. First, they saw themselves as a point of contact between the members and the board: "we're like tentacles that can pick up on things that are working well or going badly wrong". The respondents noted that part of their job was to pick up on the latest news, rumors, complaints and other issues of importance to the forest owners out in the villages and pass them on through appropriate channels so that they could be addressed. Mostly, these concerned operational matters, in which case the owners' concerns were generally passed on to forest inspectors (professionals employed by the association to advise members and procure timber). If it concerned member/owner issues they could discuss it in the district council or take it through appropriate channels in the organization, to the board or management. In such instances, the general opinion was that transfer of information was working quite well because forest inspectors and representatives of the board often attended council meetings. Outward communication, i.e., communication from the council to association members within the districts, was considered to be more difficult. This was partly due to a lack of good communication channels such as e-mail lists or text messaging systems that could be used to distribute information to district members. Another reason was that information was not always passed on, or was passed on slowly, by the board and the association's management. This was partly because much of the economic and strategic information the board and management possessed was considered to be confidential and sensitive to the interests of the association as a business.

The respondents who were not chairs of their district councils said that they were rarely contacted by forest owners regarding forest related issues; some were even unsure whether the members knew that they were representatives for their districts. One said: "I never get any calls concerning forest owner issues, except when you called and a few from the female forest owners' section for some interview or something. But otherwise, I hear very little from the members. I don't even know whether most of them are aware that I am a representative, because not everybody attends the annual meeting".

A second role, which was related to the provision of information, was that the respondents saw themselves as ambassadors for the association with a duty to promote it to both existing and potential new members: "My own role is to, in my area, present the benefits of membership in Norra skogsägarna and to get them (other forest owners) to understand that it is the association they should sell to and not to the other companies".

One thing that the respondents did not include into their role as ambassadors was the direct recruitment of new members by getting them to sign a membership form. This task was left to the forest inspectors, who were considered by many respondents to be the most important people in terms of 
marketing the association. This is because they go out in the field and make more contact with people who are contracting for harvesting operations, which is the point at which most forest owners sign up.

The third, and perhaps most work-intensive, role related to the councils' responsibilities for member activities such as forest days as well as arranging courses in forestry or forest economics, social activities and fairs. These activities are the core functions of the association's member organization and are the occasions at which board members have the most contact with members.

Finally, one respondent stated that the association's organization (i.e., the management and board) has high expectations of the council members, and that it can be hard to live up to those expectations. As she explained it: "I don't really know what extraordinary people that are supposed to become representatives in that case. It is not like we are ready-made marketers and educators...and I don't know if such people can be found, for that matter".

The roles expressed by the respondents can be compared to the organization's expectations which can be found in its written guidelines. These state that the council and its representatives should [35]:

- Support the forest inspectors by planning and carrying out member activities that promote the recruitment of new members, as well as timber contracting;

- Provide a link between the forest owners and the forest inspectors for the transfer of both feedback on existing business and the possibilities for new contracts and recruiting new members;

- Be a consultative body for the association's board;

- Monitor local issues relating to family forestry and in appropriate ways co-operate with the local branch of LRF.

\subsection{Organizational Attributes}

The attribute of the organization that the respondents mentioned most often was its honesty. They had a strong belief in that the association always treats them fairly and that the organization always sees to the best of its members. They argued that this is what makes the associations different from other companies, whose first priority is the interest of their stockholders. In some cases, the forest companies were described as thieves whose only purpose is to fool forest owners about money, just as they did during the times when the association was founded. A key component in this perceived honesty was the organization's transparency regarding pricing. Other forest companies may publish their price lists, but the association has not the same freedom to deviate from the price list and negotiate for better terms with individual sellers even if it could be a good deal for both parties. This security aspect was emphasized by one of the respondents: "If you sell to the association, you know that you never will be fooled because the association, per se, has no profit interest in the same way that they should be able to divide money to shareholders. Instead, if there is a profit, then we get better prices or other returns".

The historical attribute to act as a counterweight towards the investor-owned companies was thus still seen as important by the respondents. However, respondents added that this difference might be hard to see as long as the organization exists and the market functions according to the association's objective, but they were certain that it would become visible if the association would not be competing with the companies on the timber market. 
Another attribute mentioned by several respondents as being one of the most important things that the association stands for, was its work on political issues regarding landowners' rights. This was also perceived as a service that distinguishes the association from the companies and which respondents thought should get more attention and visibility within the organization.

Some respondents also saw the association as an important part of their own businesses. Their long term partnership with the association gave them important close personal contacts and a strong and mutually beneficially cooperation that helped both the individual and the association.

The respondents who performed a lot of forestry work themselves clearly expressed that the association should stand for good forest management practices. By "good practice", they meant both good economic growth in forestry and that the forest management should be focused on a long-term basis so that the management practice will be sustainable. Those who volunteered in order to get more understanding of how to manage the forest better themselves, by learning best practice from the association, can also be linked to this attribute.

\subsection{Relationship to the Organization}

The respondents had early been introduced to the association through their fathers and other relatives who had been members. Because of this natural connection, they had attended meetings and activities arranged by the association and developed connections with the forest inspectors who work for the association. This gave them an introduction to the association and made it easier for them to join, but also made it easier for the organization to recruit them since they knew each other personally.

The respondents said that both before and after they became active in the organization, it was the forest inspectors who were the most important people in the relationship between forest owners and the organization. The respondents noted that in some senses, the forest inspectors are more important than the organization itself. By this they meant that it is with the individual that forest owners make personal bonds and if that person were to leave the organization, the forest owner might follow him to another organization. They therefore considered it important for the association to keep the same forest inspector for a long time in the organization and give them possibilities to meet forest owners in the field. Some respondents complained that the turnover of forest inspectors had been too high in recent years, and that this was making it harder for the district councils who had to build new relationships with the newly hired inspectors.

In general the respondents were satisfied with how the cooperation between the district boards and the forest inspectors and region managers was working. These groups were reported to participate regularly in council meetings and to generally be able to answer the council's questions. It was noted that the forest inspectors tell the council the latest news from inside the company. Each district also has a person from the association board who acts as their contact person and who often attends the district meetings in order to form a closer connection between the district councils and the association board.

However, the district council members do not have access to business or strategic information that would give them a full understanding of the association's business situation and plans for the future. The information they received was said to be of a more general nature that could be openly communicated. This suggests the existence of a hierarchical information system within the association, in which the CEO and senior management have the most information, together with the association's 
board. Information is then distributed downwards to the chairmen of the different councils, who in turn evaluate what he/she will communicate to the rest of the council, or whether it should be distributed to all of the district's members. Only very limited amounts of information about the association and its business operations seem to be passed all the way down to the members (the owners) and so their understanding of the organization is limited to the information they get from other members or representatives of the association with whom they have personal contact.

This way of handling information was widely accepted by the respondents and they did not question the system as such. The respondents noted that they had elected the board to govern the management of the association and so they need to be confident that the board will act in the best interests of the association's members.

The non-business aspects of the relationship between the association and its members are mainly established via the activities organized by the councils. As explained in the previous section, the councils are responsible for organizing forest days, various courses (on subjects such as forest management, economics, tax-planning, etc.), and social events. Both forest inspectors and member representatives attend these events, making them good opportunities for members to develop relationships with people inside the organization and to get more information about it.

\subsection{The Chairpersons' Conferences-A Forum for Influence}

Twice per year, the chairs of the district councils gather for a meeting to discuss member/owner issues together with the association's board and management. The conference usually runs for two days, with one day being allocated for the managers to provide up-to-date information on the state of the association and the market conditions. On the second day, the chairs discuss issues raised by the district councils. A group of four people, one from each region, is given the responsibility of setting the agenda for the second day. One of the respondents that had participated in this group said that the conferences had developed greatly in recent years and that he personally had put a lot of effort into getting this change. Previously they had largely been based around one-way communication from the board and management, with little input from the chairs and districts. Now he said that they could act more as a consultative body for the board and that day two is dedicated to issues that are important to the members.

These conferences have no formal decision-making authority but are considered to have significant influence on upcoming decisions and the strategic direction of the association. The respondent who participated in the organizing group argued that these conferences are more important for strategic work than the association's general annual meeting. The reason was that: "At an annual meeting, if someone is well-spoken he can get support from the delegates. But that can end really badly. Just because something sounds fantastic doesn't mean it's been well thought out-the speaker might not have the same information that we do. The annual meeting is a bit erratic in that way. Therefore the conferences are better, because then you can examine the issues more carefully and as "what happens if we do this?' We don't have those discussions at the annual meetings'.

Similar views regarding the importance of these conferences were expressed by other respondents, who also thought that the change described previously has been positive because more issues where discussed from their (member) perspective. The (indirect) involvement of district council members in 
the decision-making process was considered to be important; one respondent stated that: "Even if a highly educated, intelligent and competent CEO or other executive would have made the same decision by themselves, the decision would have had less legitimacy than if it has been first discussed among the member representatives".

\subsection{Election Committee}

As discussed previously, the election committees have a strong and important role in the association and its renewal process because of their strong influence on the composition of the councils and the association board. The election committee's mission is to find suitable candidates for the different positions in the association and to make suggestions to be voted on at the annual district council meetings. These suggestions are usually accepted without debate at the annual meetings. The election committees often consist of previous or current council members or other respected persons within the organization. Their members are formally elected at the annual meeting. This is not unique to for the forest owners' associations but is the typical way of how election processes are conducted within many Swedish organizations.

There is also an association-level election committee, which identifies and recommends potential board members. It has two working guidelines in addition to those specified in the association's statutes. These relate to functionality (group composition) and representativity (geographical spread). Its working procedure involves first asking the existing board members if they want to continue on their positions. If they do, they are normally recommended for another term. It is very rare, at both the central and the district level, for a board or council member to be "forced" to leave his or her position by not being recommended for a new term. If a board member wishes to step down at the end of their term, the committee starts its search for a new candidate. Primarily they search among the association's members because the statutes require that the board consist of people who are members of the association, belong to a member's family, or are employed by a member. Exception to these requirements can be given to maximum two persons, if their competence is considered particularly valuable for the association.

The committee therefore looks for "members with some form of front-line competence within our business area, as well as a general competence in being a forest owner, and a personality that allows them to work effectively with the group". At least some familiarity with business administration is a basic requirement, as is the ability to interpret an annual report and understand financial statements. On the district level, these requirements are not very important for the election committees to consider. Regarding the geographical spread of the board members, the respondent said that: "It's no competence to come from Umeå, Pajala or wherever... But we try to take it into account. It's important for the legitimacy of the board".

A problem in the election committee's work that was identified by a member of the committee is that there is a natural power relationship between the board/council members and the election committee, which implies that board/council members may avoid revealing information that could be perceived negatively by the committee or the members. Even when a board member decides to step down, they may not want to expose problems (if they experienced any) and instead choose to simply leave them behind and move on. This makes the election committee's work more difficult because it 
cannot take all of the relevant information into consideration when discussing nominations for the following year. On the local level, the election committees' hardest job was said to be finding people who want to volunteer for a council position, since they do not need to make the same evaluations of formal competencies as the central election committee.

\subsection{Summary}

In this section, we have described the characteristics and motives of individuals who volunteer in a forest owners' association, and examined their relationship with the association in general. We found that the characteristics of the council representatives were largely typical of traditional forest owners, with close connections to the agricultural sector, a strong personal interest in forestry and, in most cases, experience of working in their own forests. Only one respondent had forestry as their main source of income. In general, the respondents' forest holdings generated $10 \%-20 \%$ of their total income. The level of education among the respondents varied substantially and this was reflected in the respondents' occupations. We also found that the election committees had a strong influence on the respondents' decisions to volunteer, especially for those who were initially less familiar with the association's work. A wide range of motives for volunteering were identified. There was a notable difference between the male and female respondents in that the men stated that the power to influence the direction of the association was important in their initial decision for volunteer whereas among women, this factor only gained importance over time.

The respondents had in general the same views regarding their own and the association's mission. They were optimistic about their possibilities to have influence in the association and stated that they were satisfied with its current democratic situation. The recent improvements to the organization of the chair's conferences were important in this respect.

\section{Discussion}

\subsection{Traditional Groups of Members Are Involved}

Several previous studies have shown that the forest owner collective has become more heterogeneous and that their values and objectives as owners are shifting towards increased focus on recreational activities and less on purely economic factors [1,5-7]. Since the member bases of the forest owners' associations have grown in recent years, it may be assumed that the heterogeneity of the member bases have increased to a similar extent. However, these new types of forest owners do not seem to have made their way on to the district councils, which still seems to be dominated by traditional forest owners. If the current trends continue and the value gaps between new and traditional owner groups become wider [7], it could create complicated challenges for the associations, both in terms of their main objectives and in terms of organizational structure. If the associations only support the interests of a diminishing group of traditionalists, their reproduction cycles might not work efficiently as the replenishment of new members and volunteers becomes harder [22,27] and their existence will be threatened. Our analysis revealed a few factors that could partially explain why the involvement of new members in the association's district councils has been limited so far. 
First, we found that most of the council members lived close to their forests, did some amount of forestry work themselves, and focused on production and economically efficient forestry practices. This was as expected given the association's history and mission. However, as was shown by authors such as Nordlund and Westin [7], these values might not be shared by the new types of forest owners, who might be more interested in recreational values and place less emphasis on forest revenues. It might thus be that younger members do not identify strongly with the organization, or the people in it, in a way that would encourage them to become more active and involved members, e.g., by volunteering as a council representative. We find support for this idea in a study by Lidestav and Arvidsson [15] who observed differences in how members of a forest owners' association identify themselves depending on their background and the amount of forestry work they performed. Members who perform forestry work themselves often identify themselves as "forest managers" while those who buy all their forest services identify as "forest owners". They also found forest inspectors and the association's managers have different ideas about how forest owners identify themselves and how the professionals define members' relationships with the association, e.g., as owners (of the cooperative), members, suppliers or customers. There seems to be a somewhat messy situation in which groups inside the organization have different perceptions and assumptions about one-another and the organization itself, although the interviewed council members all had quite similar views. Going back to Stryjan's loop of reproduction [22], it has been argued that it is the assumptions within the organization that affect its decisions and practices, which in turn determine its development over time. If all levels in the organization have different perceptions about its members and work in different ways and with different goals for the forest owners, the renewal process will become complicated.

Based on Penner's [27] model, it was argued that the organizational attributes and practices in combination with the organization's relationships with the individuals will be important for whom to attract to the organization. If the organization has so many different ways of defining its members (and consequently many different ideas about how they should be approached), we believe that there is a potential risk that members and volunteers might become confused about their roles and relationships with the organization and thereby the association's attractiveness decreases. For example, if forest owners are only treated as suppliers or customers of the association, why should they donate their time to the association by volunteering when they can have the same supplier/customer relationship with other companies on the market? We thus agree with Lidestav and Arvidsson [15] that the language used by the organization is important both for how the organization is perceived by forest owners outside the organization as well as how people inside the organization treat members and other forest owners. In order to encourage members to become active, the organization must offer them something more than just a business relationship. Forest owners also need a personal incentive to become involved in the association's internal operations. Since the respondents in this study expressed motivational factors from 4 out of the 6 categories identified by Clary and Snyder [30], we argue that the associations have good opportunities to find attributes that attract a broad variety of people. Reasons to why we did not identify the remaining two categories (career and protective) might be that all of the respondents already had careers and did not want to share any potential personal problems in an interview with a researcher they had not met before.

Second, we found that the association's various election committees play a central role in the recruitment of new council members. This is the traditional way in which association boards are 
elected in Sweden and so is not unique to the forest association studied in this work. Due to their composition and working processes as well as the strong cultural traditions associated with the election committees, they affect the recruitment process in several ways. Since they often consist of people who support traditional values and practices, this might may be reflected in who they will ask to volunteer for the councils. Stryjan [20] does not discuss election committees specifically in his work, but he argues that selection of a certain type of members is natural as long as the environment and other conditions permit the organization to do so. The reason is that it saves costs due to less need for educating and socializing the recruited members into the organization. Therefore network recruitment and family members to current members of an association are attractive target groups, which we also could identify in this study. However, a restrictive selection process demands that the recruitment base is refilled and this is to larger extent depending on the environment than on the organization itself. As described in the introduction of this paper, the societal development is changing forest owners' values, needs and objectives and thereby the traditional recruitment base is decreasing. This means that this selection process will become more difficult in a near future when the old networks disappear as members retire or passes away. To avoid that the recruitment base of new district council members continue to decrease it will thus be important that new groups of members and thereby new networks are introduced to the organization.

However, as we saw in this study, none of the council members interviewed stated that they had actively run for a position without support from the election committees. This might not be uncommon for the Swedish context as Einarsson found that $28 \%$ of the population in his study was interested in becoming a member representative if they were asked to [23]. The selective recruitment strategies are thus barriers to the involvement of forest owners with qualifications that do not relate to handling a chainsaw and who are interested in forestry for reasons other than production. Since the election committee system is so deeply rooted in the association's practices and culture, it might be hard for potential volunteers to step forward and aspire to council positions even if they were interested in doing so. Further, because the election committees are reluctant to suggest changes in the council's composition against anyone's wish to continue on their position it often demands that any of the current council member decides not to run for re-election. However, if committees always take the easy way out and just suggest the re-election of current council members without actively searching for new people or holding discussions about their future strategies and the work of the council, the renewal process in the councils will remain very slow. Instead the organization will only be upholding existing organizational structures and practices until the pool of attractive candidates is empty.

We are aware that it in many cases can be a challenging situation for the election committees and the association since many of the council members have been involved for a long time and identify strongly with the association. It may therefore be emotionally difficult for them to give up their positions, since doing so would create a vacuum in their daily routines. The association should thus offer alternatives to those who are not re-elected but wish to continue contributing their time and to maintain their involvement with the association. The election committees also need to have good arguments for their suggestions, and be able to communicate them, in order to avoid placing too much focus on personal issues rather than the association's interests. Being replaced should not mean that one has no future as a volunteer in the association, which seemed to be a risk in the current organizational culture. Because reproduction is an ongoing process (and a very slow one in the current environment), 
we do not expect that any major changes will occur in the short term. In the long term, if the organization becomes aware of the risks of the current system and develops more systematic processes out in the districts (as they seem to have done for the general election committee), the system could be used to the association's advantage. The election committee could place more social pressure on members to take responsibility for the association, which Penner [27] argued to be an important initial factor in decisions to volunteer.

Third, as expected, characteristics such as education and social status seem to have little importance in volunteering decisions within forest owners associations (at least at the local level) despite having been identified by Wilson [26] as increasing the likelihood of volunteering. Involvement with the associations is still primarily founded on values and tradition, which implies that replenishment occurs primarily from the traditional types of forest owners. The type of employment seems to be more important, since it affects their ability to contribute time to the organization as well as their need for social contact outside the workplace. This might create challenges regarding the recruitment of new volunteers because of the changing characteristics of the labor market. Since fewer people have isolated jobs, it might become harder to motivate them to volunteer in order to get social contact. Social media and other technological advancements could also reduce the need for people to meet in physical environments in order to satisfy their social needs.

Fourth, it seems that only limited amounts of information regarding the organization's internal affairs reach the "normal" members. Access to information is largely controlled by the management and the chairpersons who attend the chairs' conferences. The association's magazine has a broader target group than its member base and thus cover limited amount of internal member/owner issues. The annual district meetings are therefore the association's most important information channels, along with other occasions at which members can interact physically with representatives of the management and the board. However, as discussed above, only a small proportion of the members attend these meetings $[14,15]$. In combination with the identity issue previously discussed, this creates barriers for the members to get committed to the association. We consider it unlikely that such members will be encouraged to get involved if they have limited knowledge or understanding of the association's work. We will return to this issue later on when discussing the roles of the council members within the association.

Finally, before ending this section, we need to remember that the forest owners' associations are hybrid organizations that consist of two parts (as described in Figure 1) with different operating conditions and logics. The business organization is more flexible and moves faster than the member organization. Therefore, it is not only a matter of language and profiling but also an issue of organizational structures and objectives which will be of interest for the associations in a long-term perspective. It is possible that the associations will have to address the fundamental question of whether their constituted purpose should continue to solely be the promotion of the members' economic interests if future forest owners become less interested in such issues. It will thus be necessary to perform further analyses of their organizational structure and ability to meet the challenges created by changing business relationships. Some of these challenges will be discussed in the following sections but many of the organizational issues will remain unanswered and could be of interest for future research within this area. 


\subsection{Role Identity}

Penner [27] argued that over time, the volunteers in an organization will develop a role identity that relates to the organization they are involved in. Similarly, Stryjan [22] argued that a shared frame of reference among the members of an organization is important for the reproduction process because it affects how individuals interpret situations and the actions they take in response. As expected, we found that council members had shared perceptions regarding their roles in the organization. However, before discussing these roles and the council members' views, it is important to note that their answers were very similar to the roles outlined in the organization's official documents. It is thus possible that they have taken some of their answers from this document rather than giving their completely personal view of their role and the organization's attributes. On the other hand, some of the respondents probably participated in the development of this document, which could explain the similarities. With this in mind, we will examine the views expressed by the respondents concerning their roles.

First, they saw themselves as important transmitters of information between the members and management. However, they also noted that they are rarely contacted by members and in one case the respondent was not even sure that members knew that she was a council member. We can also assume that when an increasing number of members are living in cities, and the council members often live in rural areas, the distance between the council members and the members might increase, reducing the frequency of spontaneous contact between them. It might thus be hard for the council members to fulfill their mission or role as they claim to do at present. It could therefore be useful to create new forums that would facilitate the communication of information in both directions in order to ensure that this role is fulfilled in the future.

Second, the lack of communication with members and forest owners in general might explain why the council members did not consider themselves to be very important in the recruitment of new members. Even though they say they try to act as ambassadors and promote the association to forest owners, much of the responsibility for this process is placed on the forest inspectors since the current membership is so closely connected to the business transaction. Already today, but especially on long-term, we consider it problematic that so much of the responsibility for both recruitment and communication is put on the forest inspectors' and the professional organization, whose main task is to buy wood and not to inform about the association from a members perspective. As explained previously, employees do not always have the same view of the forest owners as those who are involved in the association and instead see them more as suppliers/customers [15]. Therefore, if the recruitment process is largely left to the employees, it will be less apparent to new members that there are differences (if there are) between the association and other companies on the market. In the long run, this could make it harder to get people involved in the association if the only connection members have with the organization is through business contacts. If voluntary involvement in the association is to continue, we consider it essential for council members to develop closer relationships with their members. To succeed with such an ambition it might be necessary for the association to evaluate its current organization. For example, one could ask whether the organization should still be organized into 27 districts in which membership is determined by the location of the member's forest holdings and not the individual's location, when the trend is that the people concentrate into cities. We will 
return to this issue in the next section and discuss it in relation to the members' possibilities to exert influence.

Finally, we found that the organizational identity was very strong among those who are active within the organization. Considering that they all had been connected to the association for a long time this is not surprising since identity is something that grows stronger with time spent in the organization [27]. Honesty, transparent pricing, sustainability (e.g., long-term perspectives on planning) are attributes that the association is perceived to stand for by the council members. Further we found a very strong faith among the council members towards the organization, believing that it always has its members' interests at heart. The fact that all respondents stated that the most important thing about the association is its honesty towards its members is something that the organization should keep in mind when doing business.

From our perspective, we argue that while this strong organizational identity can act as a strength for the association in that it helps to maintain the enthusiasm of long-term volunteers, it can also be seen as a threat if the frames are not compatible with the surrounding environment, as the pool of potential members will diminish due to a lack of identification with the organization, and the council members' actions will not stimulate the renewal process. We further argue that council members need to get more involved in the recruitment process and in communicating with their members, and that the association needs to find new tools for these purposes. Otherwise, there is a significant risk that when long-term volunteers step down in future, there might not be anyone interested in taking their places because they have not been sufficiently introduced to the association.

\subsection{Possibilities for Members to Exert Influence}

Members' input into the organization, and the organizations ways of handling them, was argued by Stryjan [22] to determine how it will develop in the future. In general, the respondents considered that their ability to influence the organization was good in some respects but that it takes a lot of work if you want to make any bigger changes. The association gives all members the right to send in suggestions to the association's annual meeting, which ensures that all members can at least make their suggestions known. As in all democratic groups, for ideas to be taken further it is necessary for their proponents to gather support among other groups. This might be difficult for many members, especially for those who are not living in the same district as their forest is located and where they thus are members. The physical distance and lack of daily contact with other members in the area might decrease the members' possibility to seek support for their ideas. It might also decrease the activity in the democratic process since fewer members have the possibility to attend meetings in locations that are far from their homes. While members of other districts can attend local meetings to get information, they have no voting rights and thus have less power to influence decisions.

The development of the chairs' conferences seems to have given some new energy to at least some of the members involved in the organization and to have increased the legitimacy of the organization's democratic processes in the eyes of the district council members. The respondents' views on the democratic process were in general very pragmatic. They had an understanding of that managers need to make decisions quickly and cannot always ask the member representatives before doing so. Our findings thus indicate that the growing size of the business has created conditions similar to those 
described by Jussila and Goel [25]. However, this does not yet appear to have reduced the general trust in the organization as was predicted by Nilsson et al. [16], at least not among the interviewed council members, who were very confident in their belief that the managers would act in the best interests of the association and its members. If this is their true opinion, the council representatives differ from other members who were reported to be skeptical about the motives of the association's employees by Lidestav and Arvidsson [15]. One explanation for the different levels of trust between the groups could be due to different perceptions regarding participation in the organization's democratic control systems, as discussed by Österberg and Nilsson [17]. Because council members have more insights and stronger positions in the governance of the association, they may become less critical towards the board and management than members with limited participation.

There is thus a risk that if the representatives become too naïve in their beliefs and are insufficiently skeptical regarding the objectives of the managers, there will be an unnoticed increase in administrative power, causing the association to follow the common path for democratic organizations outlined by Chaves and Sajardo-Moreno [18]. Based on the issues discussed in this paper we consider the association to be situated in the third phase of this path. It is clear that the managerial power is strong due to their control over information and influence in decision-making processes and there was an understanding among the respondents that managers need to make quick decisions on a fast moving market and that they cannot always consult with members in this process. Also, much of the responsibility for recruitment and other activities were left to professionals, meaning that ordinary members might have limited insight and knowledge about the association's democratic processes. However, there are also findings that indicate that the association has not yet moved into the final administrative phase. Since the involved district council members are familiar foresters and have good knowledge about forest operations they also understand the association's business under what conditions it is operating. The initiatives they have taken to develop the chairperson's conferences and their demand for better dialogue with management in the decision-making process are important factors that slow down the development towards increased managerial. We do not consider it likely that the association will take a step backwards on this path but what will happen when these involved and committed district council members leave the organization will be an interesting issue to follow. In this paper we have discussed a few issues which the current organization could work with so that also tomorrow's organization will be an association controlled by its members, for the benefit of its members.

As it was stated in the introduction to this paper a member can contribute with four types of inputs to the organization's reproduction process. These were: involvement, protest/voice, loyalty and exit [20,22]. However, since this paper only have focused on the first two of these and studied a group of members with a strong relationship to the organization we should remember that we will not have a complete picture of the inputs made by members to the reproduction process. The majority of member is found in the group of loyal but passive members and there might also be members that try to influence through other forums than by visiting formal meetings or by becoming a district council member. Nevertheless, however these members act they will also have an impact on the association that we have not captured in this study. For future research it could thus be of interest to investigate how the organization handles people with more radical ideas and who might use other ways to influence than the traditional democratic procedures. There are probably many members who go directly to the professional management with their concerns and this might have implications on the member 
organization in long-term due to changed practices on the business side. Finally, studying former members who have left the organization could identify weaknesses in the association's current profile and practice and also give valuable information on how the composition of members is changing.

\section{Conclusions}

Both Stryjan's reproductive perspective and Pennner's model of sustainable volunteerism offer good starting points when striving to understand why people decide to become involved in organizations such as the forest owners' associations and how the members can affect their development. They therefore offer associations a tool that they can use in the process of renewing themselves in order to ensure that they remain attractive to the next generation of forest owners.

We found that today the district councils are populated by traditional forest owners with diverging motives for their involvement in the organization's affairs. This is positive for the association because it means that it should be possible to motivate many different types of forest owner to get involved. The challenge for the association is thus to reach out to these members in a way that can attract them and make them interested in more than just doing business transactions with the association.

As we have shown, it is very important that the associations actively consider how they want to be perceived by both current and potential members. However, this alone will not be sufficient: the associations also need to find new ways to communicate and build stronger relationships with their current members that are based on factors other than business transactions. From what we have seen, the information flow out to the members could be improved in order to give them a better understanding of what is going on inside the association and their possibilities to act as members/owners. This should increase their interest in getting involved. The council members have important roles to play here because, as discussed, they may have stronger incentives than the managers to increase member involvement in the association's internal life. This is illustrated by the development of the chairs' conferences in recent years.

Finally we can conclude that the election committees will continue to play a crucial role in the recruitment of new council members and will thereby determine how the association will evolve in the coming years. It would thus be beneficial for the association if the district-level election committees were to become more active in their searches for new candidates and to adopt the same kind of strategic thought in their recruitment process as the central election committee. Of course, this requires that there many candidates to choose among. However, as we have shown, people are more likely to become volunteers if they are asked than if they need to take the first step by themselves. By approaching forest owners other than those who already sit on councils or belong to networks with such individuals, the councils could be made more heterogeneous and thus more representative of the member base as a whole.

\section{Acknowledgments}

This study was conducted as part of a research project funded by Norra Skogsägarna. The authors gratefully acknowledge Erik Jonsson for many useful discussions. 


\section{Conflict of Interest}

The authors declare no conflict of interest.

\section{References}

1. Berlin, C.; Lidestav, G.; Holm, S. Values placed on forest property benefits by Swedish NIPF owners: Differences between members in forest owner associations and non-members. Small Scale For. Econ. Manag. Policy 2006, 5, 83-96.

2. Wennebro, T. En Samlad Kraft: Norra Skogsägarna 75 år (in Swedish); Norra Skogsägarna: Umeå, Sweden, 2008; pp. 17-21.

3. Swedish Forest Agency. Swedish Statistical Yearbook of Forestry 2012; Swedish Forest Agency: Jönköping, Sweden, 2012; pp. 22-36.

4. Normark, F. Medlemsägda Företag: Organisering av Strategiska Förändringar (in Swedish). Ph.D. Thesis, The Stockholm School of Economics, Stockholm, Sweden, September 1994.

5. Ingemarson, F.; Lindhagen, A.; Eriksson, L. A typology of small-scale forest owners in Sweden. Scand. J. For. Res. 2006, 21, 249-259.

6. Karppinen, H. Values and objectives of non-industrial private forest owners in Finland. Silva Fenn. 1998, 32, 43-59.

7. Nordlund, A.; Westin, K. Forest values and forest management attitudes among private forest owners in Sweden. Forests 2011, 2, 30-50.

8. Inglehart, R. Globalization and postmodern values. Wash Quart. 2000, 23, 215-228.

9. Swedbank. LRF Konsult, Skogsbarometern 2012. Available online: http://www.lrfkonsult.se/ PageFiles/5540/SKOGSBAROMETERN2012.pdf (accessed on 24 January 2013).

10. Vogel, A.; Amnå, E.; Munch, I.; Häll, L. Associational Life in Sweden: General Welfare Production, Social Capital, Training in Democracy. Report 98, Statistics Sweden, Stockholm; SCB-Tryck: Örebro, Sweden, 2003.

11. Putnam, R.D. Bowling Alone: The Collapse and Revival of the American Community; Simon \& Schuster: New York, NY, USA, 2000.

12. Einarsson, T. Medlemskapet i Den Svenska Idrottsrörelsen (in Swedish); EFI Civil Society Reports: Stockholm, Sweden, 2008; pp. 53-60.

13. Norra Skogsägarna. Stadgar för Norra Skogsägarna Ekonomisk Förening (in Swedish). Available online: http://www.norra.se/upload/pdf-filer/Stadgar\%20för\%20Norra\%20Skogsägarna_2011.pdf (accessed on 28 August 2012).

14. Echeverri, P. Bortom Ideologi Och Ekonomi: Lantbrukskooperation, Medlemsinflytande Och Strategiutveckling i Förändring (in Swedish); Research Report; Karlstad University: Karlstad, Sweden, 2006.

15. Lidestav, G.; Arvidsson, M. Member, Owner, Customer, Supplier? The Question of Perspective on Membership and Ownership in a Private Forest Owner Cooperative. In Global Perspectives on Sustainable Forest Management; Okia, C.A., Ed.; InTech: Rijeka, Croatia, 2012; pp. 75-94.

16. Nilsson, J.; Kihlén, A.; Norell, L. Are traditional cooperatives an endangered species? About shrinking satisfaction, involvement and trust. Int. Food Agribus. Manag. Rev. 2009, 12, 101-122. 
17. Österberg, P.; Nilsson, J. Members' perception of their participation in the governance of cooperatives: The key to trust and commitment in agricultural cooperatives. Agribusiness 2009, 25, 181-197.

18. Chaves, R.; Sajardo-Moreno, A. Social economy managers: Between values and entrenchment. Ann. Public Coop. Econ. 2004, 75, 83-96.

19. Jonsson, E. En Samlad Spaning; Norra Skogsägarna: Umeå, Sweden, 2009.

20. Stryjan, Y. Impossible Organizations: On Self-Management and Organizational Reproduction. Ph.D. Thesis, Uppsala University, Uppsala, Sweden, December 1987.

21. Bussell, H.; Forbes, D. Understanding the volunteer market: The what, where who and why of volunteering. Int. J. Nonprof. Volunt. Sect. Mark. 2002, 7, 244-257.

22. Stryjan, Y. Understanding cooperatives: The reproduction perspective. Ann. Public Coop. Econ. 1994, 65, 59-79.

23. Einarsson, T. Membership and Organizational Governance. Ph.D. Thesis, Stockholm School of Economics, Stockholm, Sweden, October 2012.

24. Giroux, N. Participation and strategic decision-making in a cooperative. Ann. Public Coop. Econ. 1992, 63, 5-24.

25. Jussila, I.; Goel, S. Cooperation and Conflict: Four Perspectives on Governance of Co-Operatives. In Proceedings of the 13th Conference of the International Association for the Economics of Participation, Mondragon University, Mondragon, Spain, 13-15 July 2006.

26. Wilson, J. Volunteering. Annu. Rev. Sociol. 2000, 26, 215-240.

27. Penner, L.A. Dispositional and organizational influences on sustained volunteerism: An interactionist perspective. J. Soc. Issues 2002, 58, 447-467.

28. Malmqvist, J. The Next Generation's View on Forest Ownership and the Forest Owner Association; Swedish University of Agricultural Sciences: Umeå, Sweden, 2010.

29. Statistics Sweden. Arbetskraftsundersökningarna (AKU) december 2012. Available online: http://www.scb.se/Pages/PressRelease__347811.aspx (accessed on 4 February 2013).

30. Clary, E.G.; Snyder, M. The motivations to volunteer: Theoretical and practical considerations. Curr. Dir. Psychol. Sci. 1999, 8, 156-159.

31. Norra Skogsägarna. Annual Report 2011; Norra Skogsägarna: Umeå, Sweden, 2012.

32. Ritchie, J.; Lewis, J. Qualitative Research Practice; SAGE Publications: London, UK, 2003; pp. $78-80$.

33. Pointdexter, C.C. Meaning from methods: Re-presenting narratives of an HIV-affected caregiver. Qual. Soc. Work 2002, 1, 59-78.

34. Coffey, A.; Atkinson, P. Making Sense of Qualitative Data; SAGE: Thousand Oaks, CA, USA, 1996.

35. Norra Skogsägarna. Guidelines for District Councils. Available online: http://www.norra.se/ upload/pdf-filer/skog\%20broschyrer/Sbo-handledning_07.pdf (accessed on 28 August 2012).

(C) 2013 by the authors; licensee MDPI, Basel, Switzerland. This article is an open access article distributed under the terms and conditions of the Creative Commons Attribution license (http://creativecommons.org/licenses/by/3.0/). 